\title{
Botrytis cinerea Infection in Grape Flowers: Defense Reaction, Latency, and Disease Expression
}

\author{
Markus Keller, Olivier Viret, and F. Mary Cole
}

First author: Washington State University, Irrigated Agriculture Research and Extension Center, Prosser, 99350; second author: Swiss Federal Research Station for Plant Production of Changins, 1260 Nyon, Switzerland; and third author: Monash University, Frankston, Victoria 3199, Australia.

Accepted for publication 24 October 2002.

\begin{abstract}
Keller, M., Viret, O., and Cole, F. M. 2003. Botrytis cinerea infection in grape flowers: Defense reaction, latency, and disease expression. Phytopathology 93:316-322.

Inflorescences of field-grown grapevines (Vitis vinifera L. cv. Gamay) were inoculated with a Botrytis cinerea conidia suspension or dried conidia at different stages during bloom in moist weather. Approximately $10 \%$ of the conidia germinated within $72 \mathrm{~h}$, resulting in two to three times more latent infections than uninoculated controls in pea-size $(7 \mathrm{~mm}$ in diameter) berries. In surface-sterilized pea-size berries, latent $B$. cinerea was present predominantly in the receptacle area. After veraison, latent $B$. cinerea also was found in the style and, in mature berries, latent colonies were distributed throughout the pulp. Inoculation at full bloom led to the highest disease severity (66\%) at harvest, compared with $38 \%$ in controls. Stilbene stress metabolites in the flowers were measured by

was found in necrotic tissues only, and pterostilbene and $\alpha$-viniferin were not detected at all. B. cinerea conidia suspensions also were applied to various locations on flowers of pot-grown cvs. Pinot Noir and Chardonnay. Inoculation of the receptacle area, but not that of the stigma and ovary, resulted in latent infections. Stilbene synthesis was similar to the field results, with resveratrol accumulating mainly in the calyptra and receptacle area. Constitutive soluble phenolic compounds (mainly derivatives of quercetin and hydroxy-cinnamic acid) were present at high concentrations in the calyptra but at low levels in the receptacle area. These experiments confirmed bloom as a critical time for B. cinerea infection in grapes and suggest that the most likely site of infection is the receptacle area or cap scar exposed at anthesis. Stilbenes may have a limited role in inhibition of flower infection and latency in susceptible grape cultivars, and $\varepsilon$-viniferin may be a by-product rather than a deterrent of infection.
\end{abstract} high-performance liquid chromatography. Resveratrol accumulated mainly after pre-bloom and full-bloom inoculation, but did not prevent infection. Piceid levels did not change following inoculation, while $\varepsilon$-viniferin
Additional keywords: flower infection, piceid, resveratrol, stilbene, viniferin, Vitis vinifera.
Botrytis cinerea Pers.:Fr. is a ubiquitous fungal pathogen that causes gray rot on a large number of economically important agricultural and horticultural crops. It opportunistically infects wounds or senescing tissue and also invades young tissues, causing necrosis. The $B$. cinerea fungus is present in vineyards as part of the environmental microflora. Infection of grape often occurs at bloom time, followed by a period of latency, during which the pathogen is present (quiescent or latent) inside the berry without causing disease symptoms, generally until grape berries begin to ripen $(21,23,24)$. Damage to the berries by cracking of the cuticle from pressure within the berry and physical damage from insects, hail, and wind predispose clusters to berry infection and, together with wet conditions, lead to disease expression (bunch rot) and fruit loss. Flower infection is believed to be an important stage in the epidemiology of $B$. cinerea in grape (23), but very little is known about the relationship between early infection and latency and its importance for disease control. Moreover, there is a lack of quantitative information on the relationship between flower infection and fruit rot at harvest.

Establishment of efficient management strategies against this important pathogen is hindered by a lack of basic knowledge of the plant-pathogen interactions. More detailed information could be used to define critical periods for spray programs and to devise alternative disease management strategies aimed at enhancing the

Corresponding author: M. Keller; E-mail address: mkeller@wsu.edu

Publication no. P-2003-0106-01R

(C) 2003 The American Phytopathological Society vine's natural defense mechanisms, which could ultimately result in a reduction of fungicide use in vineyards. In addition to several constitutive barriers, one important way in which grapevine tissues defend themselves against fungal attack is the accumulation of phenolic stress metabolites or phytoalexins, termed stilbenes, in response to infection $(7,28)$. Stilbene production is elicited by polysaccharide fragments from fungal cell walls and other fungal molecules which induce de novo synthesis of enzymes such as phenylalanine ammonia-lyase (PAL), stilbene synthase (STS), and the intermediary enzymes of the general phenylpropanoid pathway $(8,20)$. However, the dynamics of stilbene accumulation during the infection process and the role of individual stilbenes are not well understood. Moreover, many pathogens are capable of metabolizing and detoxifying phytoalexins, which results in plant susceptibility (31). This is also true of the major stilbene, resveratrol (3,5,4'-trihydroxystilbene), and one of its derivatives, pterostilbene (3,5-dimethoxy-4'-hydroxystilbene), which are both degraded by stilbene oxidase, a laccase-like enzyme secreted by $B$. cinerea during infection $(3,29)$. Hence, although stilbene accumulation often is seen as the main defense reaction in a variety of plant species, including the grapevine Vitis vinifera L., it does not always seem to limit pathogen penetration.

The capacity for stilbene synthesis in plant tissues is genetically determined. All members of the family Vitaceae are able to produce stilbenes, but the $B$. cinerea-resistant American Vitis spp. and interspecific hybrids generally show a much higher capacity for stilbene synthesis than the susceptible European $V$. vinifera cultivars (2). Nevertheless, developmental and environmental signals and the physiological status of the plant can have a significant impact, because the formation of phenolics and the activities of 
the enzymes involved are under the control of various external and internal factors. Although stilbene accumulation in young, green $V$ vinifera grape berries is thought to stop or at least delay $B$. cinerea infection, this defense mechanism appears to be abandoned during grape ripening $(1,13)$. However, it is unclear if stilbenes also play a role in flower infection. We are not aware of any studies reporting on a potential relationship between stilbene production and disease resistance of grape flowers. The ability of flowers to accumulate stilbenes could potentially reduce primary and latent infections and enhance overall resistance of the ripening berries to bunch rot. The purposes of this study were to (i) locate the infection court of $B$. cinerea on grape flowers and the pathogen's (latent) location in the berry, (ii) establish a link between infection and stilbene accumulation in flowers, and (iii) determine the relationship between stilbene accumulation and resistance of flowers to infection. In addition to the data presented in this paper, the infection process and establishment of $B$. cinerea within the flower and developing berry was investigated in detail using light microscopy and scanning and transmission electron microscopy and will be published separately.

\section{MATERIALS AND METHODS}

Field experiment. Mature, field-grown grapevines ( $V$. vinifera cv. Gamay on Couderc 3309 rootstock) were used during the 1998 growing season. The experimental vineyard was located on Lake Geneva at the Swiss Federal Research Station for Plant Production of Changins, Nyon, Switzerland. The vineyard was planted with a vine-by-row spacing of 0.8 by $2 \mathrm{~m}$ in north-south orientation, with a permanent floor cover of resident plants. The vines were cane-pruned to eight nodes and trained to a single Guyot system with vertically positioned shoots. Soil and canopy management, as well as downy and powdery mildew control (five applications of $0.125 \%$ folpet and $0.3 \%$ wettable sulfur between 25 May and 29 July) were carried out as for a commercial vineyard and were identical for all treatments. No specific botryticides were applied, but folpet, a contact fungicide belonging to the phthalimide family, has been reported to have a partial side effect on $B$. cinerea (4). All experimental treatments were replicated in three randomized plots consisting of 13 vines with one cluster per shoot, separated by buffer vines and rows. All inflorescences of each experimental vine were inoculated with $B$. cinerea conidia at pre-bloom (calyptra or cap attached, 9 June), full bloom (stamen exposed, 15 June), or post-bloom (stamen necrotic or dropped, 22 June). Conidia were produced and harvested as described by Pezet and Pont (26). Wet inoculations were carried out by dipping whole inflorescences in glass beakers containing a conidia suspension $\left(1.8 \times 10^{6}\right.$ conidia $\mathrm{ml}^{-1}$ of water). Dry inoculations were done by holding individual inflorescences in a 200-ml Erlenmeyer flask and dusting them with $10 \mathrm{mg}$ of dried conidia (9) from an open Eppendorf tube, using a 60-ml syringe as an air-blowing device. Three uninoculated plots were left as controls in the same vineyard.

Four to six individual flowers or berries were sampled per treatment replicate, 1, 2, and 3 days after inoculation. Germination of conidia on the flower surface was monitored by light microscopy after staining with cotton blue in lactophenol. Conidia were classified as germinated when germ tubes were about $30 \%$ the length of the conidia. At least 10 additional flowers or berries were frozen at $-80^{\circ} \mathrm{C}$ for analysis of stilbenes (described below) at each sampling date. Latent $B$. cinerea infection was assessed after fruit set (berries $7 \mathrm{~mm}$ in diameter or pea-size, 13 July), at the end of veraison (color change, 27 August), and at harvest (24 September) on at least 50 healthy-looking berries per treatment. After surface sterilization in $70 \%$ ethanol $(1 \mathrm{~min})$ followed by $1 \%(\mathrm{vol} / \mathrm{vol})$ $\mathrm{NaClO}(3 \mathrm{~min})$ and three rinses in sterile water, berries were cut in sections 3 to $5 \mathrm{~mm}$ thick. The sections were incubated on potato dextrose agar (with aureomycin) at room temperature $\left(18\right.$ to $20^{\circ} \mathrm{C}$ ) for 5 days, and appearance of mycelial growth was used for localization of latent infection. Just prior to, but on the same day as, commercial harvest (24 September), 30 to 50 clusters were monitored in each treatment and assessed for $B$. cinerea incidence (percent infected clusters) and severity (percent infected berries per cluster) by grouping the clusters in six classes: 0,1 to 10,11 to 25,26 to 50,51 to 75 , and 76 to $100 \%$ infection.

Pot experiments. Inflorescences of six pot-grown $V$. vinifera cv. Pinot Noir cuttings with one shoot and one inflorescence thinned to 20 flowers were dry inoculated with $10 \mathrm{mg}$ of $B$. cinerea conidia as described previously. The cuttings were incubated in a controlled-environment chamber at $20^{\circ} \mathrm{C}$, half of them at $100 \%$ relative humidity $(\mathrm{RH})$ and the other half at $60 \% \mathrm{RH}$ (growth chamber 'standard'). After $48 \mathrm{~h}$, the humidity conditions were inverted for another $48 \mathrm{~h}$ to test if a change in humidity would be accompanied by a change in conidia germination or penetration and subsequent stilbene accumulation. Three flowers were sampled, 1, 2, and 3 days after inoculation and extracted as in the field experiment.

Individual floral organs (calyptra, stigma, or receptacle) of additional Pinot Noir cuttings (prepared as above) were inoculated with $0.4 \mu \mathrm{l}$ of $B$. cinerea conidia suspension $\left(1.8 \times 10^{6}\right.$ conidia $\mathrm{ml}^{-1}$ ) using a Hamilton microsyringe (Fig. 1). Inoculation for each position was replicated separately on all flowers of two cuttings, at pre-bloom (calyptra) or full bloom (stigma, receptacle). The cuttings, including two uninoculated controls, were kept at $100 \%$ $\mathrm{RH}$ for $72 \mathrm{~h}$. Three flowers were sampled, 1, 2, and 3 days after inoculation. The inoculated organ was cut from the rest of the flower and stilbenes extracted separately from each part. The remaining berries were retained on the cuttings until veraison to determine the presence of latent infection as described for the field experiment.

Follow-up experiments were conducted in 1999 at the National Wine and Grape Industry Centre in Wagga Wagga, New South Wales, Australia. Conidia suspensions $\left(1.6 \times 10^{5}\right.$ conidia $\left.\mathrm{ml}^{-1}\right)$ of $B$. cinerea were applied by immersion of 12 whole inflorescences of pot-grown $V$. vinifera cv. Chardonnay at pre-bloom or full bloom in a glasshouse maintained at $24^{\circ} \mathrm{C}$ and a 16 -h photoperiod. Twelve control inflorescences were dipped in water. Following inoculation, inflorescences were enclosed in plastic bags to maintain $100 \% \mathrm{RH}$. After $48 \mathrm{~h}$, the bags were perforated to gradually decrease humidity. Inflorescences were inspected daily to determine the time of sporulation or complete necrosis, and subsequently removed from the plants and stored at $-80^{\circ} \mathrm{C}$ for stilbene analysis. Asymptomatic flowers were left to develop to berries that were harvested at veraison, surface sterilized in $1 \% \mathrm{NaClO}$ for $1 \mathrm{~min}$, rinsed in sterile distilled water for $30 \mathrm{~s}$, and incubated on potato dextrose agar at room temperature for the presence of latent infection as described previously.

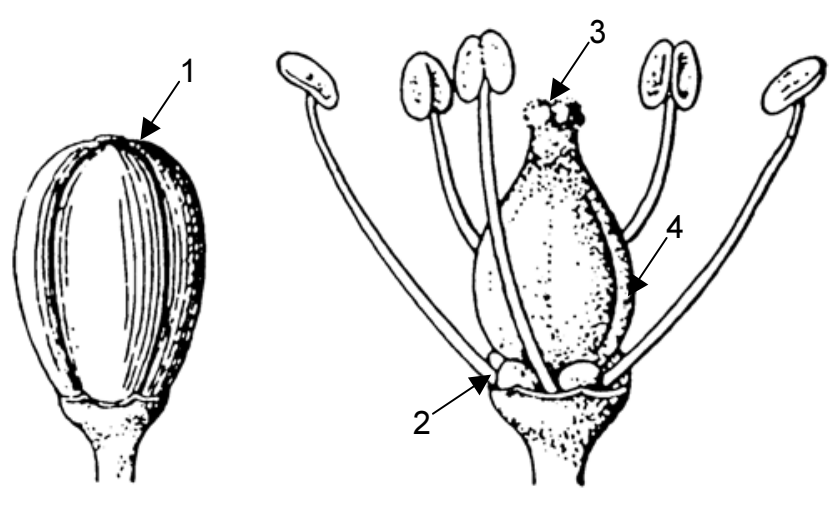

Fig. 1. Sites of inoculation of grape flowers with Botrytis cinerea conidia suspension; calyptra or cap (1), cap scar or receptacle area (2), stigma (3), and ovary (4). 
The calyptra, stigma, ovary, or receptacle of flowers of potgrown Chardonnay plants with inflorescences thinned to 30 flowers each was inoculated (Fig. 1) with $0.5 \mu \mathrm{l}$ of sterile water containing approximately 10 to 20 conidia of $B$. cinerea, using a Hamilton (Hamilton, Reno, NV) syringe with a repeating dispenser. Inoculation for each position was replicated separately on all flowers of three inflorescences on three separate plants. Inflorescences, including uninoculated controls, were bagged to maintain $100 \% \mathrm{RH}$ for $24 \mathrm{~h}$. Duplicate samples were taken for stilbene analysis at $0,1,2,3$, and 10 days, and for assessment of latent infection at 3 and 10 days. Flowers were dissected into individual organs for analysis of stilbenes.

Stilbene analysis. Stilbenes were extracted from grape flowers or individual floral organs with approximately $50 \mu \mathrm{l}$ of ethyl acetate per milligram of fresh tissue by grinding the tissue to a fine powder using a glass rod in a 1-ml glass vial. The volume then was brought to $100 \mu \mathrm{l}$ using a reference vial. Extracts were mixed using a pipette tip and solids were allowed to settle for a few seconds. The supernatant was filtered through $0.45-\mu \mathrm{m}$ polypropylene membranes and transferred to $150-\mu$ l sample vial inserts, after which 20 to $40 \mu \mathrm{l}$ were injected into a Varian highperformance liquid chromatography (HPLC) system (Varian Associates, Walnut Creek, CA), consisting of a 9012 Solvent Delivery System, 9300 Autosampler, and 9065 Polychrom Diode Array Detector. Phenolics were separated on a 250-by-4-mm LiChrospher 100 RP-18 $(5 \mu \mathrm{m})$ column (Merck, Darmstadt, Germany) preceded by a 4- by 4-mm C18 guard column. The mobile phase was $2.5 \%$ ( vol/vol) aqueous acetic acid and acetonitrile with gradient elution as described previously (16). The flow rate was $1 \mathrm{ml} \mathrm{min}{ }^{-1}$, detection by ultraviolet (UV) diode array, and quantification at $306 \mathrm{~nm}$ using the Varian Star Chromatography Workstation (version 5.5).

Ethyl acetate also extracted additional, constitutive, phenolic compounds (hydroxy-cinnamic acid derivatives and flavonols) from grape tissues. Though extraction of these phenolics was only partial, it would have been proportional to the amounts present in the tissue. Thus, these additional compounds detected on HPLC chromatograms still could give a valid indication of differences among different tissues and between treatments. Absolute concentrations cannot be compared with published data from other studies; therefore, we decided to report only peak areas for these compounds.

Data analysis. The Statistica software package (StatSoft, Tulsa, $\mathrm{OK})$ was used for statistical data analysis. Main effects were tested using analysis of variance, and Fisher's least significant difference test was used for post-hoc comparison of means. Values for stilbene analysis often did not follow normal distribution; therefore, these data were tested using the nonparametric KruskalWallis analysis of variance. Correlation analysis was used for selected variables.

\section{RESULTS}

Field experiment. Pre-, full-, and post-bloom inoculation of Gamay flowers with $B$. cinerea conidia in the field generally resulted in less than $10 \%$ conidia germination within 3 days, regardless of whether a conidia suspension or dried conidia were used (Table 1). Nevertheless, the high numbers of conidia applied ensured that at least several germinated conidia were found on every flower examined. This resulted in up to $20 \%$ of berries with a latent infection at pea-size and veraison and almost $100 \%$ at harvest (Table 2). The fewest latent infections were found in uninoculated controls, but there was no clear relationship between the timing of inoculation and latency. While latent infections were completely restricted to one or the other of the berry sections up to the end of veraison, this was not true at harvest. Thus, latent $B$. cinerea infections were mostly confined to the receptacle area of pea-size berries but, at the end of veraison, they also were found in the style, and at harvest the pathogen was present throughout the entire berry (Table 2). Few saprophytic fungi (mainly Alternaria spp., Fusarium spp., and Epicoccum spp.) were present after surface sterilization. They were generally confined to the pedicel at pea-size, but also were found throughout the berry after veraison. B. cinerea inoculation increased both disease incidence and severity at harvest. However, although inoculation time had no effect on latent infections, inoculation at full bloom resulted in the highest disease incidence (Fig. 2). Dry inoculation led to $46 \%$ higher disease incidence $(P<0.001)$ and $66 \%$ higher disease severity $(P=0.027)$ than wet inoculation (data not shown).

Resveratrol accumulated in floral tissues after inoculation with $B$. cinerea conidia and was at a maximum 2 to 3 days after preand full-bloom inoculation (Table 3). Traces of resveratrol were found as late as 14 days after inoculation and also in necrotic flowers, but no resveratrol was detected in uninoculated controls. Many inoculated flowers also failed to produce resveratrol, and resveratrol accumulation was not related to conidia germination. Only the trans-form, but not the cis-isomer, of resveratrol could be detected in flower tissues, indicating that the latter is not likely to occur in young, intact tissues under natural conditions. The resveratrol-3-glucoside, piceid, was found after inoculation at full bloom and post-bloom (less with pre-bloom inoculation), as well as in uninoculated controls (Table 3). Piceid concentration increased throughout the measuring period. $\varepsilon$-Viniferin (resveratrol dimer) could be detected only in necrotic (infected) flowers ( $\leq 2 \mu \mathrm{g} / \mathrm{g}$ fresh weight [fw]) 10 days after inoculation (data not shown). However, $\varepsilon$-viniferin was absent before the appearance of necrosis, even when an abscission layer clearly had been formed and the flowers appeared darker than normal, healthy tissue. Some necrotic calyptras that were still attached to post-bloom berries also contained $\varepsilon$-viniferin (data not shown). No pterostilbene or $\alpha$ viniferin could be detected in any tissues.

TABLE 1. Botrytis cinerea germination on the surface of Gamay grape floral organs as a percentage of applied conidia at various times after inoculation of inflorescences in the fieldy

\begin{tabular}{|c|c|c|c|c|c|c|}
\hline \multirow[b]{2}{*}{ Time $^{z}$} & \multicolumn{3}{|c|}{ Dry inoculation (dried conidia) } & \multicolumn{3}{|c|}{ Wet inoculation (conidia suspension) } \\
\hline & Calyptra & Ovary & Stamen & Calyptra & Ovary & Stamen \\
\hline \multicolumn{7}{|c|}{ Pre-bloom } \\
\hline 1 day & 8.2 & $\ldots$ & $\ldots$ & 11.4 & $\ldots$ & $\ldots$ \\
\hline 3 days & 9.7 & $\ldots$ & $\ldots$ & 6.9 & $\ldots$ & $\ldots$ \\
\hline \multicolumn{7}{|c|}{ Full bloom } \\
\hline 1 day & 2.2 & 11.1 & 8.6 & 4.8 & 4.4 & 5.0 \\
\hline 3 days & $\ldots$ & 4.9 & $\ldots$ & $\ldots$ & 7.1 & $\ldots$ \\
\hline
\end{tabular}

y Values are means of 4 to 6 samples; ... indicates missing organs.

${ }^{\mathrm{z}}$ Inoculation and sampling time. Sampling time = number of days (24-h intervals) after inoculation. 
The prominent constitutive phenolic compounds extracted from flower tissues (data not shown) were flavonols (particularly glycosylated quercetin derivatives) and esters of hydroxy-cinnamic acid derivatives (mainly the trans- and cis-isomers of caffeyl- and coumaryltartaric acid). The concentration of caffeyl- and coumaryltartaric acids increased during bloom, while quercetin derivative concentration (but not amount) decreased. None of the constitutive phenolics responded to $B$. cinerea inoculation, except that hydroxy-cinnamic acid contents in necrotic tissues were 13 to 19 times lower than in green tissues $(P<0.001)$.

Pot experiments. Incubation of inoculated Pinot Noir inflorescences in $100 \%$ RH for 2 days resulted in $88 \%$ conidia germination, but incubation at $60 \% \mathrm{RH}$ inhibited germination completely. Reversing the humidity conditions stopped additional conidia germination in the former $100 \% \mathrm{RH}$ treatment and increased germination to $44 \%$ in the former $60 \% \mathrm{RH}$ treatment. Only the fullbloom inoculation resulted in latent infection, particularly if conidia had been applied to the receptacle area, where $50 \%$ of inoculated flowers developed latent infections, compared to $10 \%$ following inoculation of the stigma, and none in the controls (data not shown).

In the glasshouse, $100 \%$ of inoculated Chardonnay inflorescences led to berries with latent infection, compared with $18 \%$ latency in uninoculated controls. Many infected flowers, and sometimes whole inflorescences, became necrotic and were aborted. Sixteen different isolates of $B$. cinerea were recovered from surface-sterilized Chardonnay berries, suggesting that the vines also had been naturally infected in addition to the artificial inoculation. Latent infection following inoculation in the receptacle area was identical to the field observations, but inoculation of the stigma and ovary generally did not lead to infection, even though conidia did germinate on these organs (data not shown).

Stilbene synthesis in Pinot Noir flowers was similar to the field results obtained with Gamay flowers, but concentrations were generally lower than in the field. Accumulation of stilbenes did not seem to prevent infection. Resveratrol, piceid, and traces of $\varepsilon$ viniferin were found 2 days after post-bloom inoculation at $100 \%$ $\mathrm{RH}$, but only piceid was present at $60 \% \mathrm{RH}$ (data not shown). Resveratrol was present exclusively in inoculated flowers, where-

TABLE 2. Latent Botrytis cinerea in Gamay grape berries at the pea-size stage $(2 \times 25$ berries per plot), end of veraison $(3 \times 30$ berries per plot $)$, and harvest $(3 \times 30$ berries per plot) following inoculation of inflorescences with a conidia suspension at pre-, full, or post-bloom ${ }^{\mathrm{w}}$

\begin{tabular}{lcccc}
\hline & \multicolumn{3}{c}{ Berry sections $(\%)^{\mathrm{y}}$} & \\
\cline { 2 - 4 } Time & Style & Ovary & Receptacle & Berries $(\%)^{\mathrm{z}}$ \\
\cline { 2 - 4 } Pea-size & $P=0.62$ & $P=0.62$ & $P=0.05$ & $P=0.05$ \\
Pre-bloom & 0 & 2 & $20 \mathrm{a}$ & $22 \mathrm{a}$ \\
Full bloom & 0 & 0 & $12 \mathrm{ab}$ & $12 \mathrm{ab}$ \\
Post-bloom & 2 & 0 & $8 \mathrm{bc}$ & $10 \mathrm{~b}$ \\
Control & 2 & 2 & $2 \mathrm{c}$ & $6 \mathrm{~b}$ \\
Veraison & $P=0.15$ & $P=0.06$ & $P=0.40$ & $P=0.31$ \\
Pre-bloom & 11 & 0 & 8 & 19 \\
Full bloom & 7 & 0 & 13 & 20 \\
Post-bloom & 6 & 2 & 10 & 18 \\
Control & 0 & 0 & 8 & 8 \\
Harvest & $P=0.01$ & $P=0.05$ & $P=0.006$ & $P=0.59$ \\
Pre-bloom & $49 \mathrm{a}$ & $58 \mathrm{ab}$ & $50 \mathrm{bc}$ & 99 \\
Full bloom & $58 \mathrm{a}$ & $72 \mathrm{a}$ & $68 \mathrm{a}$ & 100 \\
Post-bloom & $53 \mathrm{a}$ & $73 \mathrm{a}$ & $60 \mathrm{ab}$ & 100 \\
Control & $28 \mathrm{~b}$ & $50 \mathrm{~b}$ & $37 \mathrm{c}$ & 97 \\
\hline
\end{tabular}

${ }^{w}$ Values followed by the same letter did not differ significantly $(P>0.05)$.

x Sampling and inoculation time.

y Percentage of berry sections with latent B. cinerea. Surface-sterilized berries were sectioned into style, ovary, and receptacle for detection of latent infections.

${ }^{\mathrm{z}}$ Percentage of berries with latent $B$. cinerea. At harvest, latent $B$. cinerea often was present in more than one section; thus, percentage data are not additive. as piceid could be detected in both inoculated and control flowers (Fig. 3). Moreover, piceid concentration did not change significantly following inoculation. The only stilbene detected in necrotic (infected) flowers was $\varepsilon$-viniferin, traces of which also were present in some inoculated flowers just before necrotic symptoms appeared (Fig. 3).

A pure flavonol, which was tentatively identified as quercetin3-glucuronide (on the basis of its HPLC retention time and UV absorption spectrum), was present in calyptras at high concentrations (data not shown). This compound also was found in much lower concentration in styles and ovaries, but was completely absent in the receptacle area. The concentration of this quercetin derivative was similarly high in control and inoculated flowers, but was low in necrotic and pre-necrotic flowers. Other quercetin glycosides showed high concentrations in the calyptra and intermediate levels in the style, ovary, and receptacle. There were no significant treatment differences in caffeyl- and coumaryltartaric acids, though concentrations were lowest in necrotic flowers (data not shown).

Stilbene accumulation in Chardonnay flowers was similar to the response observed with flowers of Gamay and Pinot Noir. Resveratrol was almost absent in the ovary and accumulated mainly in the calyptra and receptacle areas, regardless of the point of

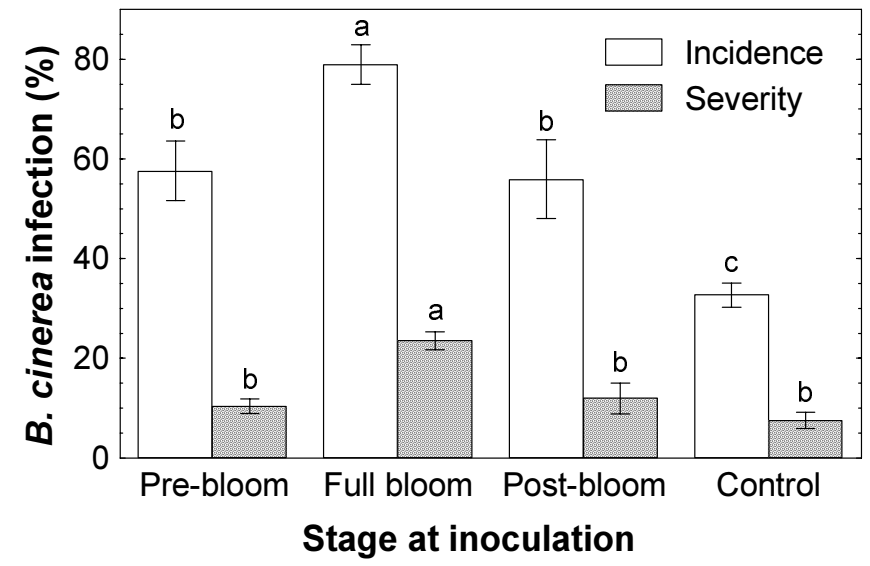

Fig. 2. Disease expression at harvest of Botrytis cinerea following inoculation of Gamay grape flowers in the field. Values are means \pm standard error $(n=6)$. The treatment effect was significant at $P=0.002$ (incidence) or $P<$ 0.001 (severity). Values followed by the same letter did not differ significantly $(P>0.05)$.

TABLE 3. Stilbene accumulation in Gamay grape flowers following inoculation of inflorescences in the field with a Botrytis cinerea conidia suspension ${ }^{\mathrm{y}}$

\begin{tabular}{lcc}
\hline Treatment & Piceid $\left(\mu \mathrm{g} \mathrm{g}^{-1} \mathrm{fw}\right)$ & Resveratrol $\left(\mu \mathrm{g} \mathrm{g}^{-1} \mathrm{fw}\right)$ \\
\hline Inoculated & $P=0.24$ & $P=0.006$ \\
Yes & 5.85 & 11.89 \\
No (control) & 3.69 & 0.00 \\
Inoculation time & $P<0.001$ & $P=0.15$ \\
Pre-bloom & $0.52 \mathrm{a}$ & 14.04 \\
Full bloom & $8.19 \mathrm{~b}$ & 8.19 \\
Post-bloom & $7.27 \mathrm{~b}$ & 0.59 \\
Sampling time & $P<0.001$ & $P=0.62$ \\
1 day & $1.24 \mathrm{a}$ & 3.37 \\
2 days & $3.83 \mathrm{a}$ & 10.98 \\
3 days & $4.82 \mathrm{a}$ & 15.12 \\
7 days & $14.14 \mathrm{~b}$ & 5.77 \\
14 days & $13.90 \mathrm{~b}$ & 5.86 \\
\hline
\end{tabular}

y Piceid and resveratrol were the only stilbenes detected. Interactions were not significant; therefore, only main effects are shown. Values $(n \geq 10)$ followed by the same letter did not differ significantly $(P>0.05)$. fw indicates fresh weight.

${ }^{\mathrm{z}}$ Number of days (24-h intervals) after inoculation. 
inoculation (Table 4). Resveratrol content was highest 1 day after inoculation and then decreased. Contrary to resveratrol, piceid was present in the ovary but not in the receptacle or calyptra (Table 4). Though the amount of piceid per flower increased during and after bloom (data not shown), its concentration decreased due to the rapid increase in fresh weight during this period. Both resveratrol and piceid also could be measured in some uninoculated control flowers. This confirms the results from $B$. cinerea isolation and suggests that a natural infection may have occurred in these flowers in addition to the artificial inoculation.

The concentrations of cinnamic acid derivatives and, particularly, quercetin derivatives in the calyptra far exceeded those in the ovary or receptacle (Fig. 4). As with Pinot Noir, quercetin-3glucuronide (but not other quercetin derivatives) was absent in the receptacle. The total amounts of both cinnamic acid derivatives and quercetin derivatives increased during the course of the sampling period, mainly in the ovary $(P<0.001)$. However, the concentration of quercetin derivatives decreased due to the rapid increase in fresh weight $(P<0.001)$. The concentration of hydroxy-cinnamic acids was slightly $(P=0.02)$ higher in inoculated flowers compared with controls, but quercetin derivatives were not affected by inoculation (data not shown). There was a close correlation between cinnamic acids and quercetin derivatives $(r=$ $0.76 ; P<0.001)$, but not between either of these and any stilbenes.

\section{DISCUSSION}

Inoculation of flowering inflorescences of field-grown Gamay grapevines with $B$. cinerea conidia increased latent infection in young berries and disease expression in ripe berries compared with naturally infected controls. Although latent $B$. cinerea mostly was restricted to the receptacle area in young berries, the fungus also invaded the rest of the berry during ripening. This is consistent with observations on strawberry fruits, where $B$. cinerea also penetrates the flower but remains confined to the receptacle until maturation (15). However, berry sampling was necessarily destructive; therefore, it was not possible to follow the progression of latent infection within the same berry. Hence, our data did not allow us to determine whether the infection spread from the receptacle area in every case, or whether some of the latent $B$. cinerea was from infection through the stigma and style or other potential sites. Nevertheless, the vast majority of $B$. cinerea growth from surface-sterilized pea-size berries originated from the

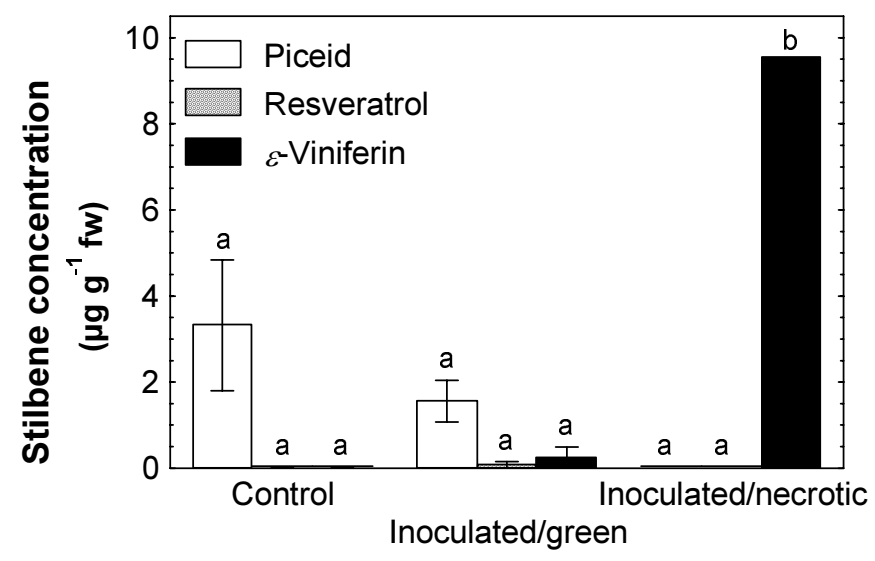

Fig. 3. Stilbene accumulation in Pinot Noir grape flowers following inoculation with Botrytis cinerea conidia in a controlled-environment chamber. Values (fw $=$ fresh weight) are means \pm standard error $(n \geq 3)$. The treatment effect was significant at $P<0.001$ ( $\varepsilon$-viniferin) or not significant (piceid and resveratrol). Values followed by the same letter did not differ significantly $(P>0.05)$. receptacle area in both the field and pot experiments; therefore, it is likely that the pathogen invaded flowers preferentially in this area at the base of the stamen. The receptacle area is exposed during 'cap fall', the shedding of calyptra, which marks the beginning of bloom (anthesis). Flower infection in grape could be related to localized necrotic areas around the abscission layer of the calyptra. In addition to the previously suggested pathway through the style (21), these 'cap scars' may be initial sites of $B$. cinerea establishment leading to latent infections. Observations of the penetration of $B$. cinerea germ tubes and hyphae into the flower using light microscopy and scanning and transmission electron microscopy confirmed this conclusion (unpublished data). Further evidence that the receptacle area is the prominent entry point for the fungus comes from the fact that resveratrol also accumulated mainly in this area, regardless of the site of inoculation in the pot experiments.

Prior to the end of veraison, approximately one out of five inoculated berries developed a latent infection; whereas, at harvest, latent infections occurred in almost all of the berries. Although the uninoculated controls showed the lowest latency and disease levels, there was no clear relationship between the timing of inoculation during the bloom period and latency. This is not so surprising if one considers the large variability in flowering times in the field, even within the same inflorescence, and the likelihood that one successful germ tube penetration is sufficient to establish a latent infection. This was confirmed in the pot experiments, where inoculation of entire inflorescences under conducive conditions always resulted in latent $B$. cinerea; whereas, when conidia were precisely applied to individual floral organs at defined developmental stages, only the inoculation at full bloom led to latent infections. Moreover, latency was assessed on surface-sterilized berries; therefore, $B$. cinerea on the berry surface was not taken into account. In view of the low percentage of conidia germination, it is likely that dormant conidia on the berry surface contributed to opportunistic secondary infections of mature berries. Thus, higher numbers of dormant conidia on the berries and flower debris inoculated at full bloom may have caused the higher disease expression in this treatment. However, even the controls showed a relatively high incidence of bunch rot. This may reflect the absence of specific $B$. cinerea control treatments in combination with rainy periods during both bloom and grape ripening (21).

TABLE 4. Stilbene accumulation in Chardonnay grape flowers following inoculation in the glasshouse with a Botrytis cinerea conidia suspension ${ }^{w}$

\begin{tabular}{lcc}
\hline Treatment & Piceid $\left(\mu \mathrm{g} \mathrm{g}^{-1} \mathrm{fw}\right)$ & Resveratrol $\left(\mu \mathrm{g} \mathrm{g}^{-1} \mathrm{fw}\right)$ \\
\hline Inoculated & $P=0.79$ & $P=0.11$ \\
Yes & 2.49 & 0.80 \\
No (control) & 2.43 & 1.10 \\
Inoculation site $^{\mathrm{x}}$ & $P=0.76$ & $P=0.38$ \\
Calyptra & 3.92 & 1.08 \\
Stigma & 1.87 & 1.27 \\
Ovary & 2.71 & 0.36 \\
Receptacle & 1.49 & 0.51 \\
Floral organ & $P<0.001$ & $P=0.004$ \\
Calyptra & $0.00 \mathrm{~b}$ & $2.93 \mathrm{~b}$ \\
Ovary & $4.81 \mathrm{a}$ & $0.05 \mathrm{a}$ \\
Receptacle & $0.00 \mathrm{~b}$ & $1.48 \mathrm{~b}$ \\
Sampling time & $P=0.79$ & $P=0.23$ \\
0 days & 0.00 & $0.82 \mathrm{ab}$ \\
1 day & 2.65 & $2.47 \mathrm{~b}$ \\
2 days & 1.92 & $1.04 \mathrm{ab}$ \\
3 days & 4.10 & $0.28 \mathrm{a}$ \\
10 days & 1.05 & $0.14 \mathrm{a}$ \\
\hline
\end{tabular}

${ }^{w}$ Piceid and resveratrol were the only stilbenes detected. Interactions were not significant, therefore only main effects are shown. Values $(n \geq 10)$ followed by the same letter did not differ significantly $(P>0.05)$. fw indicates fresh weight.

x Sites of application of $B$. cinerea conidia suspension.

y Part of flowers extracted for stilbene analysis following inoculation.

${ }^{\mathrm{z}}$ Number of days (24-h intervals) after inoculation. 
It also attests to the ubiquitous nature of $B$. cinerea and emphasizes the difficulty of establishing "true" controls under field conditions. Although every effort was made to confine fungal inoculum to the target inflorescences, we did not attempt to control conditions prior to or after artificial inoculation. Inoculations were carried out during an overcast, humid period; thus, the presence of senescent floral debris within the clusters could have provided an additional source of inoculum (14,33). Secondary infections of ripening grape berries also could explain the apparent increase in latency from veraison to harvest and the lack of a correlation between latency at harvest and the severity of bunch rot, which were assessed on the same day. The large percentage of latent infections in all sections of asymptomatic berries at harvest may have been due partly to recent penetrations of the pathogen from the berry surface, especially once a disease outbreak had occurred, supplying abundant inoculum for all berries. This suggests that the importance of the contribution of floral infection to infection at harvest diminishes rapidly the longer harvest is delayed after a disease outbreak, especially under conducive environmental conditions.

Resveratrol often accumulated in flower tissues in response to $B$. cinerea inoculation, but this was not always the case and, where production did occur, amounts varied considerably between different flowers. Moreover, both amount and concentration of stilbenes were generally lower than published values for $B$. cinerea-infected grape berries and leaves (2). The lack of a quantitative relationship between conidia germination and stilbene accumulation suggests that stilbenes did not inhibit germination, although this often is assumed to be their main function $(2,7,28)$. However, conidia germination does not by itself guarantee a successful penetration and establishment of infection. In those cases in this study where an infection was established, stilbene synthesis was obviously insufficient (in amount and speed) to prevent it, and resveratrol was likely degraded by the fungal stilbene oxidase $(3,29)$. According to Kuc (17), the accumulation of phytoalexins after fungal infection may merely be due to stress caused by the infection. Conversely, absence of resveratrol synthesis may indicate absence of an infection, even in the face of considerable exposure to inoculum. In this case, infection must have been prevented by alternative resistance mechanisms or environmental conditions. Stilbenes may play a limited role in inhibition of flower infection and latency in susceptible $V$. vinifera cultivars.

Although transient resveratrol accumulation was linked to $B$. cinerea infection, the roles of other stilbenes remain unresolved. The fact that piceid was found in many samples in which resveratrol

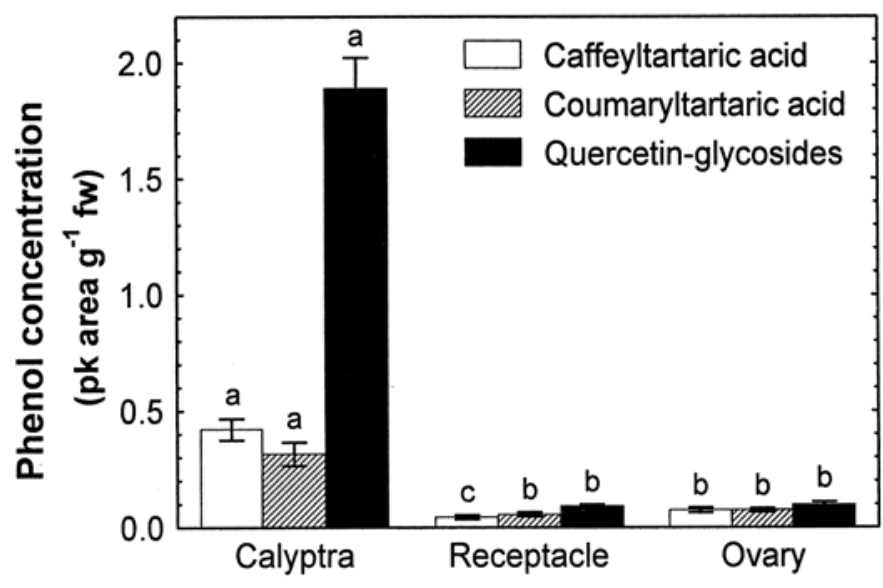

Fig. 4. Concentration of major phenolic compounds in floral organs of Chardonnay grapevines following inoculation with Botrytis cinerea conidia in a glasshouse. Values (fw $=$ fresh weight) are means \pm standard error $(n \geq 10)$. The treatment effect was significant at $P<0.001$ for all compounds. Values followed by the same letter did not differ significantly $(P>0.05)$. was not detected suggests that glucosylation may be a necessary biosynthetic step in grape flowers. However, our data are currently insufficient to draw any conclusions on the metabolic role or antifungal properties of piceid. The viniferins, on the other hand, have been proposed to be potent phytoalexins of Vitaceae (19). However, damage to plant cells and membranes during $B$. cinerea infection can lead to formation of active oxygen species, including free radicals (32), promoting peroxidase-catalyzed polymerization of resveratrol $(5,11,22)$. Hence, the late appearance of $\varepsilon$-viniferin in necrotic but not in green floral tissues suggests that its production is a result of cell damage. Synthesis of the fungitoxic $\varepsilon$ viniferin may contribute to resistance (hypersensitive response?) in older tissues $(7,19)$, whereas development of necrosis in grape flowers generally leads to abortion of these flowers. Of course, shedding infected organs could itself constitute part of a defense strategy.

No other stilbenes were detected in floral tissues, although, using the same extraction procedure, we were able to measure pterostilbene $\left(\leq 9 \mu \mathrm{g} \mathrm{g}^{-1} \mathrm{fw}\right)$ and $\alpha$-viniferin $\left(\leq 61 \mu \mathrm{g} \mathrm{g}^{-1} \mathrm{fw}\right)$ in addition to resveratrol $\left(\leq 155 \mu \mathrm{g} \mathrm{g}^{-1} \mathrm{fw}\right)$, piceid $\left(\leq 26 \mu \mathrm{g} \mathrm{g}^{-1} \mathrm{fw}\right)$, and $\varepsilon$-viniferin $\left(\leq 63 \mu \mathrm{g} \mathrm{g}^{-1} \mathrm{fw}\right)$ in grape berries infected with Plasmopara viticola (Berk. \& M. A. Curtis) Berl. \& De Toni in Sacc. (unpublished data). Pezet and Pont (25) reported very low concentrations of pterostilbene $\left(\leq 0.53 \mu \mathrm{g} \mathrm{g}{ }^{-1}\right.$ fw) in apparently healthy grape flowers, while Langcake (18) found resveratrol, $\varepsilon$ viniferin, and $\alpha$-viniferin, but not pterostilbene, in $B$. cinereainfected $V$. vinifera leaves, and Dercks et al. (7) never detected pterostilbene or $\alpha$-viniferin. We conclude that the absence of pterostilbene and $\alpha$-viniferin was not an artifact of our analytical protocol, but rather that these stilbenes are not involved in a typical grape flower-B. cinerea interaction.

The data presented here show that grape flowers produce significant quantities of constitutive flavonol-glycosides and hydroxycinnamic acid derivatives, particularly in the calyptra. Flavonols are thought to protect plant tissues from harmful UV-B radiation (12) and are essential for successful pollination in a number of plant species (6,30). In addition, flavonols as well as caffeyl- and coumaryltartaric acids can inhibit stilbene oxidase (10), and free phenolic acids contribute to an adverse environment for $B$. cinerea (27). Our observation that the receptacle area was the preferred entry point for $B$. cinerea may be linked partially to the absence in this area of a quercetin derivative (probably quercetin-3-glucuronide), which was present in all other floral organs, and to low concentrations of other flavonols and cinnamic acid derivatives. Thus, the high susceptibility of grape flowers to $B$. cinerea may be related not only to their poor capacity for stilbene synthesis, but also to low levels of constitutive phenolic compounds, particularly in the receptacle area.

\section{ACKNOWLEDGMENTS}

The Grape and Wine Research and Development Corporation, Charles Sturt University, Monash University, and the Cooperative Research Centre for Viticulture provided financial support in the form of a Visiting Research Fellowship for O. Viret; and Charles Sturt University provided a Visiting Fellowship for M. Keller. We thank J. Hatfield and J. Horsnell for technical assistance, and R. Pezet, Swiss Federal Research Station of Changins, Nyon, Switzerland, for purified stilbene standards.

\section{LITERATURE CITED}

1. Bais, A. J., Murphy, P. J., and Dry, I. B. 2000. The molecular regulation of stilbene phytoalexin biosynthesis in Vitis vinifera during grape berry development. Aus. J. Plant Physiol. 27:425-433.

2. Bavaresco, L., and Fregoni, C. 2001. Physiological role and molecular aspects of grapevine stilbenic compounds. Pages 153-182 in: Molecular Biology and Biotechnology of the Grapevine. K. A. RoubelakisAngelakis, ed. Kluwer Academic Publishers, Dordrecht, The Netherlands.

3. Breuil, A. C., Adrian, M., Pirio, N., Meunier, P., Bessis, R., and Jeandet, P. 1998. Metabolism of stilbene phytoalexins by Botrytis cinerea: 1 . 
Characterization of a resveratrol dehydrodimer. Tetrahedron Lett. 39:537-540.

4. Bugaret, Y. 2000. Le folpel en viticulture. Mesure de l'action secondaire sur 1'oïdium et la pourriture grise. Phytoma 527:36-38.

5. Calderón, A. A., García-Florenciano, E., Pedreño, M. A., Muñoz, R., and Ros Barceló, A. 1992. The vacuolar localization of grapevine peroxidase isoenzymes capable of oxidizing 4-hydroxystilbenes. Z. Naturforsch. $47 \mathrm{c}: 215-221$

6. Cheung A. Y. 1995. Pollen-pistil interaction in compatible pollination. Proc. Natl. Acad. Sci. USA 92:3077-3080.

7. Dercks, W., Creasy, L. L., and Luczka-Bayles, C. J. 1995. Stilbene phytoalexins and disease resistance in Vitis. Pages 287-315 in: Handbook of Phytoalexin Metabolism and Action. M. Daniel and R. P. Purkayastha, eds. Marcel Dekker, New York.

8. Fritzemeier, K. H., and Kindl, H. 1981. Coordinate induction by UV light of stilbene synthase, phenylalanine ammonia-lyase and cinnamate 4-hydroxylase in leaves of Vitaceae. Planta 151:48-52.

9. Gindro, K., and Pezet, R. 2001. Effects of long-term storage at different temperatures on conidia of Botrytis cinerea Pers.: Fr. FEMS Microbiol. Lett. 204:101-104.

10. Goetz, G., Fkyerat, A., Metais, N., Kunz, M., Tabacchi, R., Pezet, R., and Pont, V. 1999. Resistance factors to grey mould in grape berries: Identification of some phenolics inhibitors of Botrytis cinerea stilbene oxidase. Phytochemistry 52:759-767.

11. Hoos, G., and Blaich, R. 1988. Metabolism of stilbene phytoalexins in grapevines: Oxidation of resveratrol in single-cell cultures. Vitis 27:1-12.

12. Jansen, M. A. K., Gaba, V., and Greenberg, B. M. 1998. Higher plants and UV-B radiation: Balancing damage, repair and acclimation. Trends Plant Sci. 3:131-135.

13. Jeandet, P., Bessis, R., and Gautheron, B. 1991. The production of resveratrol $\left(3,5,4^{\prime}\right.$-trihydroxystilbene) by grape berries in different developmental stages. Am. J. Enol. Vitic. 42:41-46.

14. Jermini, M., Jelmini, G., and Gessler, C. 1986. La lutte contre le Botrytis cinerea du Merlot au Tessin: Le rôle des infections latentes. Rev. Suisse Vitic. Arboric. Hortic. 18:161-166.

15. Jersch, S., Scherer, C., Huth, G., and Schlösser, E. 1989. Proanthocyanidins as basis for quiescence of Botrytis cinerea in immature strawberry fruits. Z. Pflanzenkrankh. Pflanzenschutz 96:365-378.

16. Keller, M., Steel, C. C., and Creasy, G. L. 2000. Stilbene accumulation in grapevine tissues: Developmental and environmental effects. Acta Hortic. 514:275-286

17. Kuc, J. 1995. Phytoalexins, stress metabolism, and disease resistance in plants. Annu. Rev. Phytopathol. 33:275-297.

18. Langcake, P. 1981. Disease resistance of Vitis spp. and the production of the stress metabolites resveratrol, $\varepsilon$-viniferin, $\alpha$-viniferin and pterostilbene. Physiol. Plant. Pathol. 18:213-226.
19. Langcake, P., and Pryce, R. J. 1977. A new class of phytoalexins from grapevines. Experientia 33:151-152.

20. Liswidowati, Melchior, F., Hohmann, F., Schwer, B., and Kindl, H. 1991. Induction of stilbene synthase by Botrytis cinerea in cultured grapevine cells. Planta 183:307-314.

21. McClellan, W. D., and Hewitt, W. B. 1973. Early Botrytis rot of grapes: Time of infection and latency of Botrytis cinerea Pers. in Vitis vinifera L. Phytopathology 63:1151-1157.

22. Morales, M., and Ros Barceló, A. 1997. A basic peroxidase isoenzyme from vacuoles and cell walls of Vitis vinifera. Phytochemistry 45:229-232.

23. Nair, N. G., Guilbaud-Oulton, S., Barchia, I., and Emmett, R. 1995. Significance of carryover inoculum, flower infection and latency on the incidence of Botrytis cinerea in berries of grapevines at harvest in New South Wales. Aust. J. Exp. Agric. 35:1177-1180.

24. Pezet, R., and Pont, V. 1986. Infection florale et latence de Botrytis cinerea dans les grappes de Vitis vinifera (var. Gamay). Rev. Suisse Vitic. Arboric. Hortic. 18:317-322.

25. Pezet, R., and Pont, V. 1988. Mise en évidence de ptérostilbène dans les grappes de Vitis vinifera. Plant Physiol. Biochem. 26:603-607.

26. Pezet, R., and Pont, V. 1990. Ultrastructural observations of pterostilbene fungitoxicity in dormant conidia of Botrytis cinerea Pers. J. Phytopathol. 129:19-30.

27. Pezet, R., and Pont, V. 1992. Differing biochemical and histological studies of two grape cultivars in the view of their respective susceptibility and resistance to Botrytis cinerea. Pages 93-98 in: Recent Advances in Botrytis Research. K. Verhoeff, N. E. Malathrakis, and B. Williamson, eds. Pudoc Scientific Publishers, Wageningen, The Netherlands.

28. Pezet, R., and Pont, V. 1995. Mode of toxic action of Vitaceae stilbenes on fungal cells. Pages 317-331 in: Handbook of Phytoalexin Metabolism and Action. M. Daniel and R. P. Purkayastha, eds. Marcel Dekker, New York.

29. Pezet, R., Pont, V., and Hoang-Van, K. 1991. Evidence for oxidative detoxification of pterostilbene and resveratrol by a laccase-like stilbene oxidase produced by Botrytis cinerea. Physiol. Mol. Plant Pathol. 39:441-450.

30. Shirley, B. W. 1996. Flavonoid biosynthesis: 'New' functions for an 'old' pathway. Trends Plant Sci. 1:377-382.

31. VanEtten, H. D., Matthews, D. E., and Matthews, P. S. 1989. Phytoalexin detoxification: Importance for pathogenicity and practical implications. Annu. Rev. Phytopathol. 27:143-164.

32. von Tiedemann, A. 1997. Evidence for a primary role of active oxygen species in induction of host cell death during infection of bean leaves with Botrytis cinerea. Physiol. Mol. Plant Pathol. 50:151-166.

33. Wolf, T. K., Baudoin, A. B. A. M., and Martinez-Ochoa, N. 1997. Effect of floral debris removal from fruit clusters on botrytis bunch rot of Chardonnay grapes. Vitis 36:27-33. 